\title{
Evaluating Safety of Type-A Weaving Sections Using Geometric and Traffic Operational Factors
}

\author{
Venkata Mallipaddi ${ }^{1}, \&$ Michael Anderson ${ }^{2}$ \\ ${ }^{1}$ Department of Civil and Environmental Engineering, The University of Alabama in Huntsville, Huntsville, AL, United \\ States of America \\ ${ }^{2}$ Department of Civil and Environmental Engineering, The University of Alabama in Huntsville, Huntsville, AL, United \\ States of America
}

Correspondence: Venkata Mallipaddi, Department of Civil and Environmental Engineering, The University of Alabama in Huntsville, Huntsville, AL, United States of America.

Received: July 26, 2020 Accepted: September 4, 2020 Online Published: September 24, 2020

doi:10.5539/ijsp.v9n6p21 URL: https://doi.org/10.5539/ijsp.v9n6p21

\begin{abstract}
The efficiency and safety of type-A freeway weaving sections in urban areas are constrained by recurrent bottlenecks. Limited space in freeway weaving sections cause traffic congestion and crashes during peak-hours. Various factors, including length of weaving section, continuity of lanes, and number of lanes will have significant effects on the level of service and safety performance of the weaving sections. Eight years (2010-2017) of crash data in the type-A weaving sections was used in this analysis. The objective of this study aims to evaluate geometric design factors and operational factors on total crashes and each of the four crash types: rear-end, sideswipe, angle, and single-vehicle in type-A weaving sections using traditional negative binomial approach and develop crash modification factors (CMFs) to improve safety in the type-A weaving section. The results revealed that on-ramp traffic per hour, off-ramp traffic per hour, non-weaving traffic per hour, weaving ratio, length of the weaving section, direction of the freeway, width of inside shoulder, and width of outside shoulder were influencing crashes in type-A weaving sections. Furthermore, the estimated crash modification factors (CMFs) result revealed that total crashes gradually decrease as inside shoulder width increases. This implies that widening inside shoulder width have positive effects on weaving section safety. In addition, ramp metering, and advisory warning signs could improve safety in type-A weaving sections.
\end{abstract}

Keywords: crash frequency, crash modification factors, geometric design factors, operational factors, and weaving sections

\section{Introduction}

Since late 1960's, weaving areas have been a subject of great deal of research yet crashes on freeway weaving sections in urban areas continue to increase. Weaving sections on freeways experience higher crash probabilities compared to basic freeway section according to National Highway Safety Administration, (2009) and (Pulugurtha and Bhatt, 2010). More specifically, on Memorial Parkway freeway in City of Huntsville, Alabama, the weaving sections have a higher crash rate of 37.32 crashes/mile/year compared to other typical freeway crashes having a crash rate of 14 crashes/mile/year within the same county in Alabama. This shows that safety of weaving sections is of concern. To improve conditions on weaving sections, highway safety should be considered while taking decisions on roadway planning, design and operations.

The objective of this study was to evaluate type-A weaving section geometric design factors and operational factors on total crashes, rear-end crashes, sideswipe crashes, angled crashes and single-vehicle crashes and provide crash modification factors (CMFs) using cross-sectional method to reduce the crashes in the type-A weaving sections. The typical design of type-A weaving section consists of an on-ramp followed by an off-ramp connected by an auxiliary lane. Every weaving vehicle (a vehicle merging or diverging) must execute one lane change. The geometric design factors include length of weaving section, lane width, left shoulder width and right shoulder width. The operational factors include on-ramp volume, off-ramp volume, weaving volume, basic freeway volume, non-weaving volume and weaving ratio.

In this study, to better understand critical movements in the weaving sections at different times of day, time-of-day factors were included from NCHRP 365 (National Cooperative Highway Research Program) (William and Nancy, 1998) to the dataset. Traffic volumes and crashes for different weaving sections were segregated by 24 -hour periods. In this 
study, weaving crash data exhibit over-dispersion. To better handle over-dispersion, negative binomial (NB) regression method was used for analyzing the factors influencing crashes in type-A weaving sections. In addition, to reduce crashes in type-A weaving section CMFs were estimated using cross-sectional method. The cross-sectional studies were useful to estimate CMFs when there was insufficient before and after data for a specific treatment that is applied.

Very few studies on freeway weaving sections considered time-of-day factors for estimating expected crash frequencies and developing CMFs. Recognizing this gap, this study investigates the inclusion of time-of-day factors for modeling total crashes, rear-end crashes, sideswipe crashes, angle crashes and single-vehicle crashes using negative binomial regression model. To achieve the study objectives, 2,045 type-A weaving section crashes (representing eight-year crashes from 2010-2017) were used.

\section{Literature Review}

Past studies (Cassidy and May, 1991; Fitzpatrick and Nowlin, 1995; and Stewart et al, 1996) focused on operational and performance characteristics related to traffic flow conditions within the weaving section. These studies found that the number of lanes and speeds were the most critical factor in the determination of the capacity of weaving sections.

In addition to capacity, speeds and level of service, very few studies focused on traffic safety in weaving sections. Cirillo (1970) investigated the effect of length of weaving section, acceleration lanes, and deceleration lanes on crash rate. Results revealed that increase in length of weaving section effectively reduced crash rate if the average daily traffic was greater than 10,000 vehicles (Cirillo, 1970). Similarly, Pulugurtha and Bhatt (2010) evaluated the role of configuration type, length and the number of required lane changes by weaving traffic, entry volume, exit volume, and non-weaving volume on crashes in weaving areas using Poisson distribution. The results revealed that crashes decrease with increase in length of weaving section (Pulugurtha and Bhatt, 2010). Conflict rates were used instead of crash rates in Fazio et al. (1993) study, as an indicator for safety analysis on Interstate 294 in the Chicago. Results revealed that conflict rates were stabilized when the length of the weaving section exceeded 0.14 miles (Fazio et al., 1993). Golob et al. (2004) examined the safety aspects of various types of weaving sections (Type A, Type B, Type C, Type AB, Type AC, and Type BC) in five Orange County freeways of Southern California using Multivariate Probit Model (MPM). Results indicated that the safety of Type-A weaving sections is compromised by vehicle conflicts within the interior lanes (Gobol et al., 2004). These conflicts were more at off-peak periods, especially at night, and on wet roads (Golob et al., 2004). Mallipaddi and Anderson (2020) analyzed crashes on freeway and frontage road weaving sections using driver, environmental, roadway, geometrics, and operational characteristics to determine factors for the crashes. Results revealed that, rear-end crashes accounted 58.5\% of total freeway weaving crashes. (Mallipaddi and Anderson, 2020).

On the other hand, Le and Porter (2012) quantified the relationship between ramp spacing and freeway safety using NB regression modeling approach. Data for this study included freeway geometric features and traffic characteristics. The results from this study revealed that expected crash frequency increased as ramp spacing decreased and the presence of an auxiliary lane resulted in lower expected crash frequency (Le and Porter 2012). Iliadi et al. (2016) investigated the relationship between different geometric and traffic related variables that affect the safety performance of motorways weaving sections using negative binomial (NB) regression method in Netherlands. Authors from this study concluded that crash frequency of weaving sections was significantly affected by the length of the weaving section (Iliadi et al., 2016). Abbas (2016) developed safety performance functions (SPFs) for eight roadway configurations on high-speed roadways in Saskatchewan. These include 1) basic freeway inside interchange system 2) basic freeway outside interchange system 3) off ramp 4) on ramp 5) ramp influence area 6) weaving section 7) ramp terminal signalized, and 8) ramp terminal unsignalized (Abbas, 2016). The author found that AADT and length were significant predictors except for weaving section where speed also appeared as a significant predictor (Abbas, 2016).

Furthermore, Qin et al. (2006) investigated the relationship between crash occurrence and hourly volume counts for small samples of highway segments from Michigan and Connecticut using Bayesian estimation. The results revealed that hourly volume was non-linear for each of the four crash types that includes 1) single-vehicle, 2) multi-vehicle same direction, 3) multi-vehicle opposite direction, and 4) multi-vehicle intersection direction (Qin et al., 2006). On other hand, Shirani et al. (2020) developed SPFs using advanced techniques such as COM-Poisson and multiplicative adaptive regression splines methods for bicycle-vehicle crashes in Alabama. The results revealed that there was increase in bicycle-vehicle crashes at urban signalized intersections with increase in major road traffic volume, presence of bus stops and absence of right-turn lanes on minor roads.

Meanwhile, there were different methods to estimate CMFs, these methods were 1) the simple (naïve) before and after study which compares number of crashes before the treatment and after treatment; 2) the before and after study with comparison group which was similar to the simple before and after study, however, it uses a comparison group of untreated sites to compensate for the external factors that could affect the change in the number of crashes; 3) the empirical Bayes (EB) before and after study which accounts for the regression to the mean issue; 4) the full Bayes 
before and after study which is similar to $\mathrm{EB}$, however this method uses an expected crash frequency and its variance instead of using point estimate; and 5) the cross section method which was used to estimate CMFs when before and after data was missing for specific treatment (Juneyoung, 2015).

Harkey et al. (2008) estimated CMFs using cross-sectional studies. The authors found that cross-sectional studies can be used to estimate the safety effects of certain treatments on specific roadway types (e.g. shoulder width of freeway) since it is difficult to isolate the effect of the treatment from the effects of other treatments applied at the same time using the before-after methods (Harkey et al., 2008). According to highway safety manual (HSM), the CMFs can be estimated by cross-sectional studies when the date of treatment installation was unknown. Tarko et al., (1998) estimated CMFs using cross-sectional method. The authors found that cross-sectional method can be used to develop predictive model for the expected number of crashes and calculate safety impact of highway improvements by CMFs. Lord and Bonneson, (2007) estimated CMFs using the coefficient of the variable associated with treatments as the exponent of the coefficient when the form of the model was log linear. The CMF results revealed that wider lane and shoulder widths were associated with a reduction in segment related collisions (Lord and Bonneson, 2007). Park et al. (2010) evaluated the effects of freeway design elements on safety. NB regression models were used to estimate the effects of independent variables. The results from the NB model was used to estimate accident modification factors (AMFs) for on-ramp density and horizontal curves (Park et al., 2010). Juneyoung (2015) explored and developed of CMFs for single and multiple treatments. The author developed cross-sectional CMFs using generalized linear model (GLM), generalized non-linear model (GNM) and multiplicative adaptive regression splines (MARS) (Juneyoung, 2015). Qi et al. (2014) developed SPFs and CMFs for sixteen weaving sections in Houston and El Paso, Texas using Poisson regression model. The authors from this study revealed that weaving sections with longer lengths will have lower crash frequency per 1000 feet, increase in lane changes for diverging vehicles will result in more crashes in the freeway weaving sections, increasing merge traffic in the weaving sections will slightly reduce the crash risk, and increasing diverge traffic in the weaving sections will increase the crash risk (Qi et al., 2014). Al-Marafi. M.N. et al., (2020) developed CMFs for roundabouts using cross-section method. The results revealed that increasing the number of entry lanes, entry width, entry radius, traffic volume, circulatory roadway width, weaving width and speed limit had positive effects in roundabout safety.

As shown in the above-mentioned studies, very few studies have considered time-of-day factors for estimating crash frequency models in the type-A weaving sections. However, there were very few studies that have investigated the effects of safety improvements on type-A weaving sections using CMFs. This study attempts to fill this gap by developing NB models for total crashes, rear-end crashes, sideswipe crashes, angle crashes, and single-vehicle crashes in type-A weaving sections. Furthermore, CMFs were developed using cross-sectional method to evaluate the effects of freeway weaving design elements on safety,

\section{Data Collection and Preparation}

\subsection{Site Selection}

Weaving sections were generally grouped into three major types of configurations based on the minimum number of lane changes required. Figure 1 shows typical Type A, Type B, and Type $\mathrm{C}$ weaving sections.

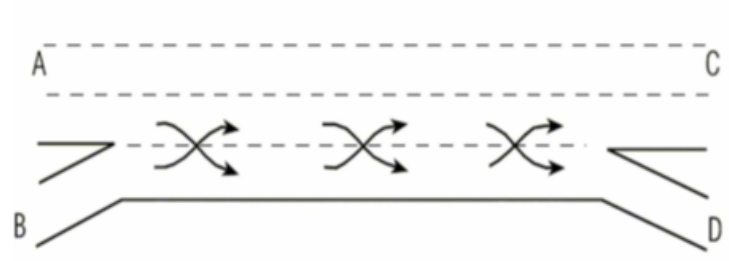

(a)

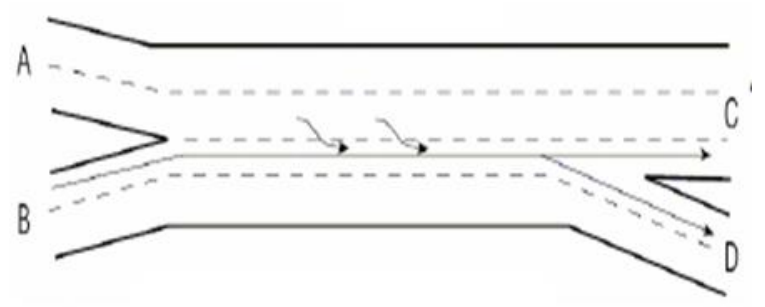

(b) 


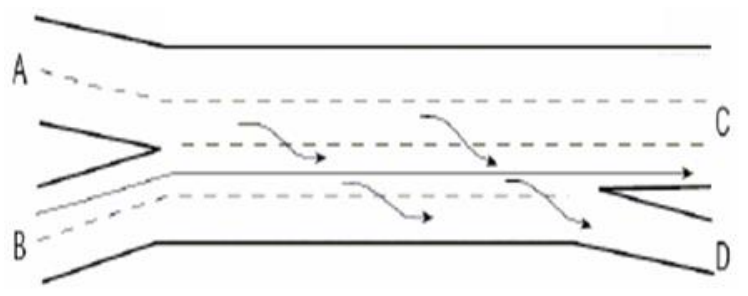

(c)

Figure 1. Type of Weaving Sections (a) Type-A (b) Type-B and (c) Type-C

Figure 1(a) shows Type-A weaving configuration where it requires a vehicle to make an at least one lane change within the weaving area (Roess et al., 2004). Figure 1(b) shows Type-B weaving section where it requires a vehicle to make two types of weaving movements. First weaving movement can be made without making any lane change while the second movement requires at most one lane change (Roess et al., 2004). Similarly, Type-C requires a vehicle to make two types of weaving movements. Figure 1(c) shows Type $\mathrm{C}$ weaving section where first weaving movement is made without any lane change and the second weaving movement requires at least two-lane changes (Roess et al., 2004).

In this study, using ArcGIS (ArcMap 10.2, 2019) and Google Earth (Google Earth Pro V 7.3, 2019) 17 type-A freeway weaving sections with different traffic volumes and geometric measurements were identified as shown in the Figure 2.

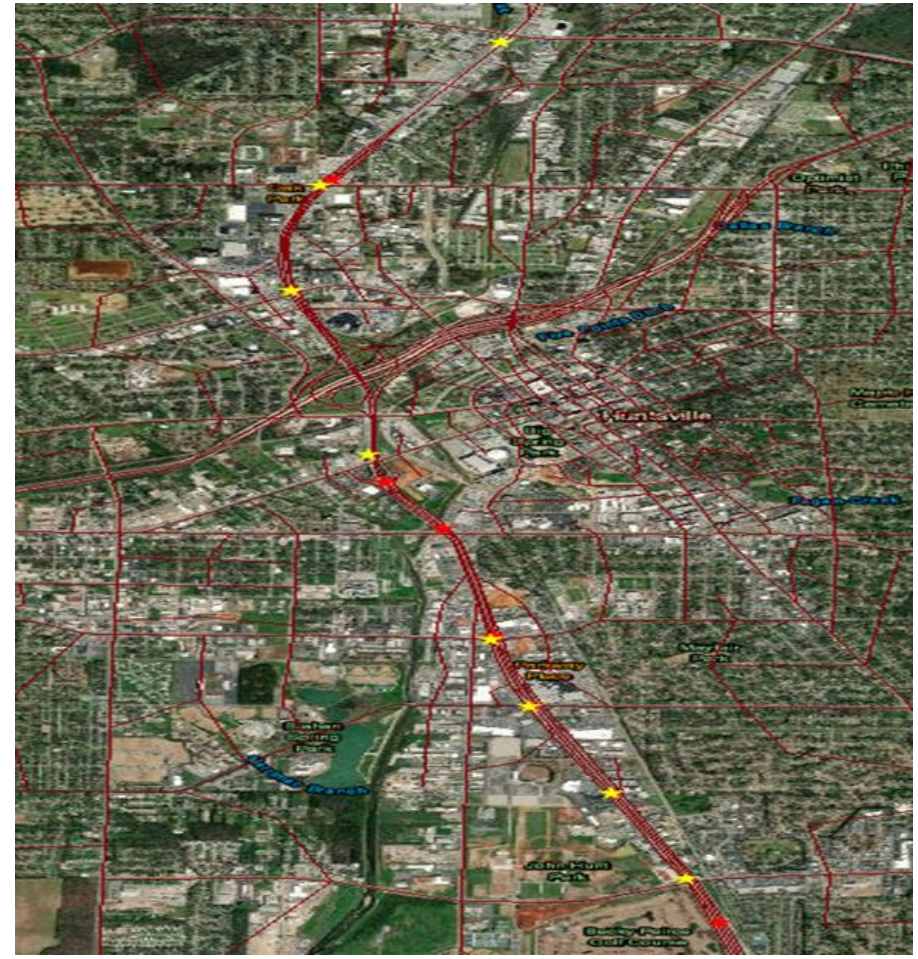

Figure 2. Selected type-A Weaving Sections (Yellow: Southbound; Red: Northbound)

\subsection{Data Collection}

\subsubsection{Geometric and Traffic Characteristics}

This section describes the data collection activities undertaken to assemble the freeway weaving database. Geometric characteristics of the freeway weaving section such as weaving section length, lane width, left shoulder width and right shoulder width were identified and measured using Google Earth. Geometric characteristics were measured for 9 weaving sections on northbound memorial parkway and 8 weaving sections on southbound memorial parkway. Figure 3 shows a sample freeway weaving section. The starting and ending points shown as yellow pins represents the weaving section length and the weaving section is displayed in red color. In this study, the weaving length was measured as the distance between points in the gore areas where the left edge of the ramp traveled way and the right edge of the traveled way meet (Skabardonis, A., and A. Kim, 2010). 


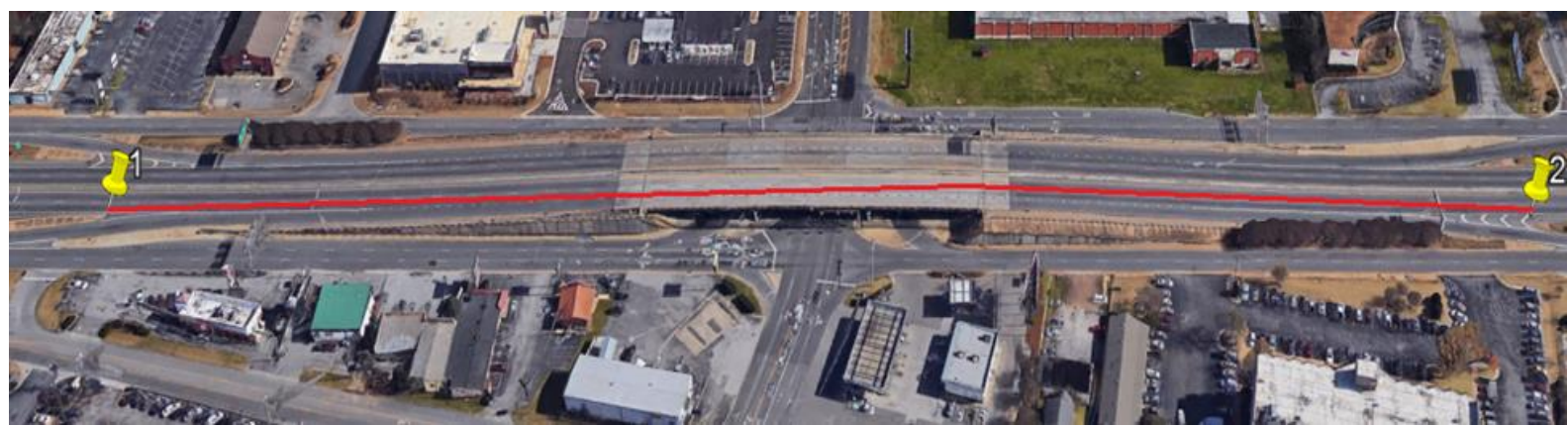

Figure 3. Sample aerial view of freeway weaving section on Memorial Parkway in Huntsville, AL. (from Google Earth Pro, 2019)

Figure 4 shows a sample aerial view of right shoulder width and lane width on freeway weaving bridge section. Note that the length measurements (weaving section length, lane width, left shoulder width and right shoulder width) were identified using the ruler tool in Google Earth.

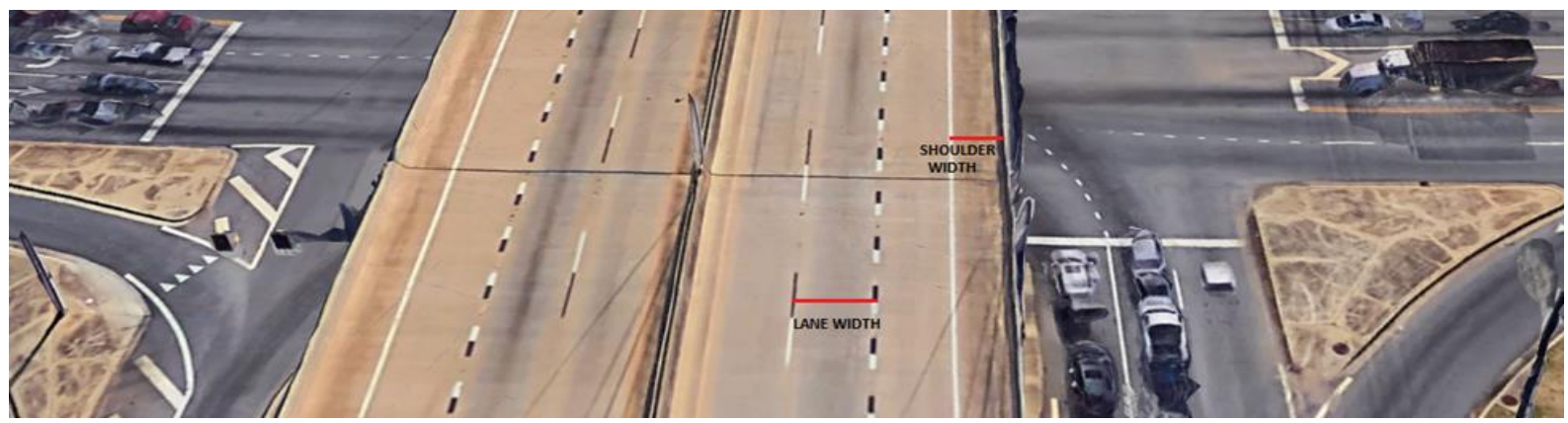

Figure 4. Sample aerial view showing lane width and right shoulder width on freeway weaving bridge section. (from Google Earth Pro, 2019)

The recent annual average daily traffic (AADT) shape files for freeway weaving section, on-ramp, off-ramp, and freeway for 2017 was available from the Alabama Department of Transportation (ALDOT) website. The ALDOT traffic count values were incorporated as part of freeway weaving section variables to be collected and were used in this study. In addition, non-weaving volume and weaving ratio were calculated. Non-weaving volume was considered equal to the freeway volume prior entering the weaving section minus the off-ramp AADT. Weaving ratio was defined as the percentage of the weaving vehicles out of the total number of the inflow vehicles to the section (Mao et al. 2019), which is calculated using equation (1).

$$
V_{R}=\frac{Q_{W 1}+Q_{W 2}}{Q}
$$

where; $\mathrm{V}_{\mathrm{R}}$ is weaving ratio (\%), $\mathrm{Q}_{\mathrm{w} 1}$ is on-ramp AADT, $\mathrm{Q}_{\mathrm{w} 2}$ is off-ramp AADT, and $\mathrm{Q}$ is the total through AADT in the weaving section.

\subsubsection{Crash Data}

Eight years (2010 to 2017) of freeway weaving related crashes on memorial parkway in Huntsville, Alabama were extracted from the CARE database, which is maintained by Center for Advanced Public Safety (CAPS) at the University of Alabama in Huntsville. The crash database contained information on the crash type and the geographic coordinates of the crash location (longitude and latitude). Based on the crash spatial location information and crash information in the CARE database, crashes that occurred in weaving sections were added to the Huntsville roadway network. Figure 5 shows crashes on Memorial Parkway weaving sections which were added to the roadway network in ArcGIS. 


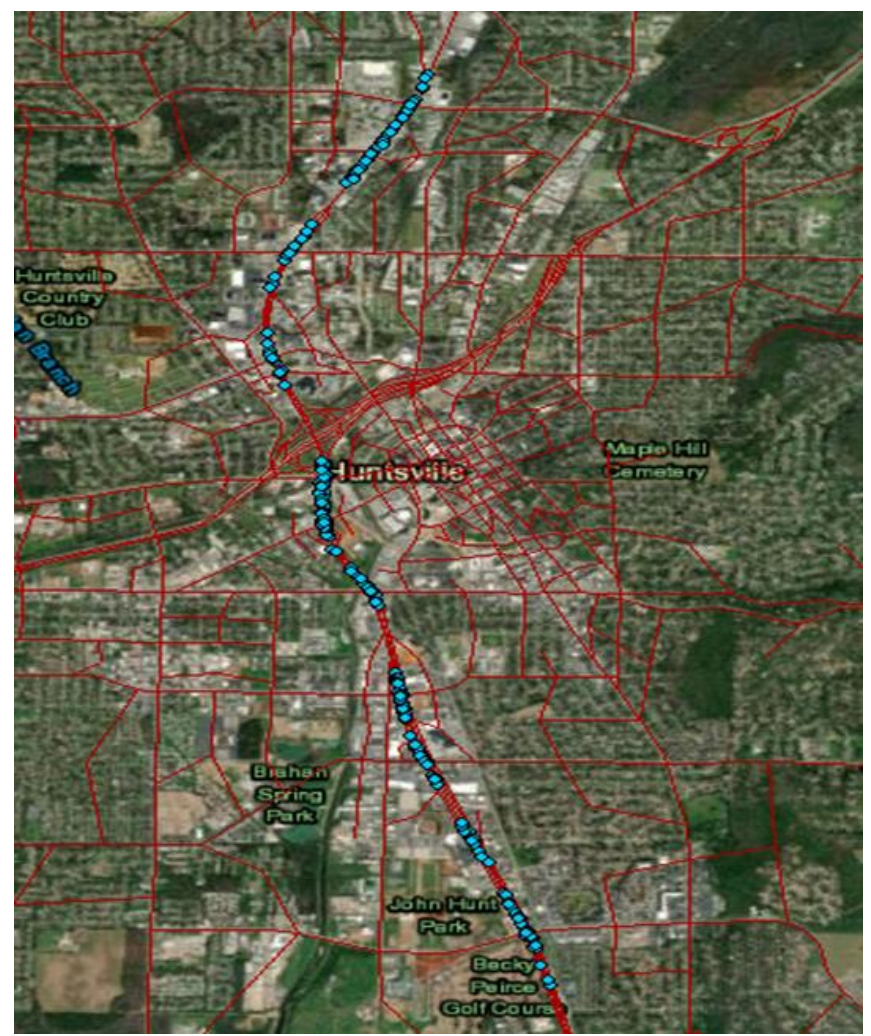

Figure 5. Weaving section crashes (Blue points: crashes)

Table 1 shows summary statistics for northbound freeway weaving sections crashes. Section sixteen experienced highest weaving crashes between 2010 and 2017 with 143 rear-end crashes. Section fourteen experienced the highest number of rear-end crashes for northbound freeway weaving sections.

Table 1. Summary Statistics for Northbound Freeway Weaving Section Crashes

\begin{tabular}{|c|c|c|c|c|c|c|c|c|c|}
\hline \multirow[t]{2}{*}{ Variables } & \multicolumn{9}{|c|}{ Northbound Freeway Weaving Section } \\
\hline & 2 & 4 & 6 & 8 & 10 & 12 & 14 & 16 & 18 \\
\hline Total Crashes & 30 & 136 & 134 & 98 & 24 & 97 & 255 & 282 & 66 \\
\hline $\begin{array}{l}\text { Rear-end } \\
\text { Crashes }\end{array}$ & 19 & 105 & 103 & 68 & 11 & 42 & 160 & 143 & 34 \\
\hline $\begin{array}{l}\text { Sideswipe } \\
\text { Crashes }\end{array}$ & 4 & 16 & 20 & 7 & 4 & 32 & 54 & 61 & 12 \\
\hline Angle Crashes & 4 & 8 & 5 & 15 & 5 & 11 & 22 & 44 & 4 \\
\hline $\begin{array}{l}\text { Single-Vehicle } \\
\text { Crashes }\end{array}$ & 3 & 5 & 3 & 7 & 4 & 8 & 16 & 26 & 14 \\
\hline
\end{tabular}

Furthermore, table 2 provides summary statistics for southbound freeway weaving sections crashes. As shown, section fifteen experienced highest number of crashes of the southbound freeway weaving sections while, section eleven experienced lowest number of crashes of the southbound freeway weaving sections.

Table 2. Summary Statistics for Southbound Freeway Weaving Sections Crashes

\begin{tabular}{|c|c|c|c|c|c|c|c|c|}
\hline \multirow[t]{2}{*}{ Variables } & \multicolumn{8}{|c|}{ Southbound Freeway Weaving Section } \\
\hline & 1 & 3 & 5 & 7 & 9 & 11 & 13 & 15 \\
\hline Total Crashes & 123 & 217 & 85 & 81 & 34 & 12 & 36 & 335 \\
\hline $\begin{array}{l}\text { Rear-end } \\
\text { Crashes }\end{array}$ & 62 & 124 & 55 & 28 & 21 & 7 & 22 & 194 \\
\hline $\begin{array}{l}\text { Sideswipe } \\
\text { Crashes }\end{array}$ & 27 & 46 & 17 & 26 & 5 & 4 & 5 & 55 \\
\hline $\begin{array}{l}\text { Angle } \\
\text { Crashes }\end{array}$ & 16 & 13 & 7 & 12 & 1 & 1 & 4 & 44 \\
\hline $\begin{array}{l}\text { Single- Vehicle } \\
\text { Crashes }\end{array}$ & 14 & 28 & 3 & 12 & 5 & 0 & 5 & 36 \\
\hline
\end{tabular}




\subsection{Time-of-Day Characteristics}

Analysis of time-of-day characteristics is required to judge safety of vehicles on weaving sections especially in urban areas (NCHRP 365). During limited periods such as peak time periods, the traffic volume is high with travelers and sometimes the traffic volume is low during off-peak hours. However, knowing about critical movements at different times of day will help in better analysis of safety. In addition, geographic location can be added as another dimension for time-of-day stratification to account for unique peaking and non-peaking characteristics of freeway weaving sections. Several studies included time-of-day analysis for traffic impact studies, trip accumulation studies and traffic system management studies, but very few studies included time-of-day analysis for traffic safety. The purpose of including time-of-day characteristics in this analysis was to determine crashes per hourly travel from estimates of total daily travel. Table 3 shows weaving sections per hour and on-ramp AADT per hour for weaving section two which were calculated using percent of vehicles trips by the hour factor. The percentage of vehicle trips by hour factors was available in NCHRP 365 report. The percentage of vehicle trips by hour factors were selected based on the city's population (200,000-499,999 for Huntsville city).

Table 3. Percent of Vehicles Trips by Hour Factors for Weaving Section Two

\begin{tabular}{|c|c|c|c|c|}
\hline $\begin{array}{l}\text { Time of } \\
\text { the Day }\end{array}$ & $\begin{array}{l}\text { Percent of } \\
\text { Vehicles Trips by } \\
\text { Hour Factor }\end{array}$ & $\begin{array}{l}\text { On-Ramp } \\
\text { AADT }\end{array}$ & $\begin{array}{l}\text { On-Ramp AADT } \\
\text { per hour }\end{array}$ & Crashes per Hour \\
\hline $0: 00$ & 0.37 & 13380 & 49.506 & 0 \\
\hline $1: 00$ & 0.21 & 13380 & 28.098 & 0 \\
\hline 2:00 & 0.29 & 13380 & 38.802 & 0 \\
\hline $3: 00$ & 0.13 & 13380 & 17.394 & 0 \\
\hline 4:00 & 0.45 & 13380 & 60.21 & 0 \\
\hline 5:00 & 0.95 & 13380 & 127.11 & 0 \\
\hline $6: 00$ & 3.42 & 13380 & 457.596 & 0 \\
\hline $7: 00$ & 7.02 & 13380 & 939.276 & 4 \\
\hline $8: 00$ & 5.31 & 13380 & 710.478 & 7 \\
\hline 9:00 & 3.61 & 13380 & 483.018 & 1 \\
\hline 10:00 & 4.13 & 13380 & 552.594 & 1 \\
\hline 11:00 & 5.26 & 13380 & 703.788 & 3 \\
\hline $12: 00$ & 6.44 & 13380 & 861.672 & 6 \\
\hline $13: 00$ & 6.04 & 13380 & 808.152 & 2 \\
\hline $14: 00$ & 7.03 & 13380 & 940.614 & 1 \\
\hline $15: 00$ & 8.4 & 13380 & 1123.92 & 3 \\
\hline $16: 00$ & 9.16 & 13380 & 1225.608 & 0 \\
\hline $17: 00$ & 9.56 & 13380 & 1279.128 & 1 \\
\hline $18: 00$ & 7.06 & 13380 & 944.628 & 1 \\
\hline 19:00 & 4.55 & 13380 & 608.79 & 0 \\
\hline $20: 00$ & 3.66 & 13380 & 489.708 & 0 \\
\hline 21:00 & 3.13 & 13380 & 418.794 & 0 \\
\hline $22: 00$ & 2.18 & 13380 & 291.684 & 0 \\
\hline 23:00 & 1.64 & 13380 & 219.432 & 0 \\
\hline
\end{tabular}

After incorporating time of day factors, 409 observations were used in this study. The datasets were divided into two datasets 1) training dataset and 2) validation dataset. Training dataset was used for developing the crash prediction models and validation dataset was used for validation of the models. The validation was used to evaluate the model's capability to predict crashes. Table 4 shows summary statistics of the explanatory variables considered in the development of the crash prediction models. Speed limit and number of lanes were not considered in this study. Speed limit and number of lanes were same for all the weaving sections. 
Table 4. Summary Statistics of Type-A Weaving Section Explanatory Variables

\begin{tabular}{|c|c|c|c|c|}
\hline $\begin{array}{l}\text { Variable } \\
\text { Description }\end{array}$ & Minimum & Maximum & Mean & $\begin{array}{l}\text { Standard } \\
\text { Deviation }\end{array}$ \\
\hline $\begin{array}{l}\text { Through AADT per hour } \\
\text { in the weaving section }\end{array}$ & 24 & 6,001 & $1,768.16$ & $1,484.37$ \\
\hline On-Ramp AADT per hour & 2 & 1,953 & $3,42.86$ & $3,68.44$ \\
\hline Off-Ramp AADT per hour & 2 & 1633 & 285.28 & 281.68 \\
\hline Non-Weaving AADT per hour & 14 & 1,968 & 653.89 & 486.54 \\
\hline Freeway AADT per hour & 22 & 3,410 & 939.18 & 691.57 \\
\hline Length of the Weaving Section (ft) & 1,246 & 4,193 & $2,150.05$ & 886.9 \\
\hline Inside Shoulder Width (ft) & 1 & 6 & 3.05 & 1.39 \\
\hline Outside Shoulder Width (ft) & 1 & 9 & 4.35 & 2.8 \\
\hline Lane Width (ft) & 10 & 12 & 11.23 & 0.54 \\
\hline
\end{tabular}

\section{Methodology}

\subsection{Model Selection and Estimation}

The crash prediction models were developed using a generalized linear models (GLM) approach. Generally, two types of GLMs were used in analyzing crash data: Poisson distribution and negative binomial (NB). In this study, the crash data was assumed over-dispersed. The phenomenon of over-dispersion occurs when the observed variance was greater than the mean of the datasets. Initially, the distributions of crash counts were assumed to follow a negative binomial distribution that deals with over-dispersion within the datasets. The value of the deviance (D) divided by the degree of freedom (DF) and the value of the Pearson chi-square $\left(\chi^{2}\right)$ divided by the degree of freedom (DF) was used for testing the NB assumption (Al-Marafi, M.N et al, 2018). The range of these values should lie between 0.8 and 1.2 in order to use NB model for developing crash prediction models.

\subsubsection{Negative Binomial (NB) Model}

NB model is an extension of the Poisson distribution and it is better suited for predicting crash frequencies. Whenever the variance exceeds the mean for a given data, the NB distribution is best suited for modeling such over-dispersed data (Qi et al, 2014). The general functional form of the NB regression model is shown in Equation 2:

$$
\ln \lambda_{i}=\beta X_{i}+\varepsilon_{i}
$$

where,

$\lambda_{i} \quad=$ expected number of crashes in 5 years on freeway weaving section;

$\beta \quad=$ vector of estimable regression parameters;

$X_{i} \quad=$ vector of geometric design, traffic volume, and other site-specific data; and

$\varepsilon_{i} \quad=$ gamma-distributed error term.

The mean-variance relationship for the NB distribution is shown in Equation 3:

$$
\operatorname{Var}\left(y_{i}\right)=E\left(y_{i}\right)\left[1+\alpha E\left(y_{i}\right)\right]
$$

where;

$\operatorname{Var}\left(y_{i}\right)=$ variance of observed crashes $y$ occurring on freeway weaving section;

$E\left(y_{i}\right) \quad=$ expected crash frequency on freeway weaving section; and,

$\alpha \quad=$ over-dispersion parameter.

The model parameters are estimated using method of maximum likelihood. The likelihood function for the NB model that is used in this study is shown in Equation 4.

$$
L\left(\lambda_{i}\right)=\Pi_{i=1}^{N} \frac{\Gamma\left(\theta+y_{i}\right)}{\Gamma(\theta) \cdot y_{i}}\left[\frac{\theta}{\theta+\lambda_{i}}\right]^{\theta}\left[\frac{\lambda_{i}}{\theta+\lambda_{i}}\right]^{y_{i}}
$$

where,

$N=$ total number of freeway weaving sections in the sample;

$\Gamma=$ gamma function; and

$\theta=\frac{1}{\alpha}$ 
To address multicollinearity, a Pearson correlation coefficient was used to assess the extent to which the continuous variables were correlated. Continuous variables that were correlated were not included in the analysis. In this study, freeway AADT per hour was found correlated with on-ramp AADT per hour, off-ramp AADT per hour and through AADT per hour. Lane width and right shoulder were found correlated. In addition, variance inflation factor (VIF) was used to evaluate correlation between continuous variables. The VIF for a given predictor variable was estimated using linear regression of that variable on all other variables in the model. A VIF less than 10 was acceptable (Kutner et al, 2005). In this study, the VIF was less than 4 for the continuous variables after the models were developed.

\subsection{Model Validation}

Mean squared error (MSE), mean squared prediction error (MSPE), mean absolute deviance (MAD) and Pseudo $\mathrm{R}^{2}$. MAD gives a measure of the average magnitude of variability of prediction, MSE measures model error associated with the estimation data and MSPE assess error associated with a validation set. A comparison of MSPE and MSE reveals potential overfitting or underfitting of the validation models to the training data (Washington et al., 2005; and Al-Marafi, M.N et al, 2018). MSPE and MSE results reveal whether the models were overfitted (MSPE > MSE) or under-fitted (MSPE < MSE). Values of MSPE and MSE that were similar in magnitude indicate that validation data fit the model similar to the training data. In general, lower values of MAD, MSE and MSPE were preferred because of low prediction error. In addition, the higher values of McFadden's Pseudo $\mathrm{R}^{2}$ indicate a better prediction performance.

MSE, MAD, MSPE and McFadden's Pseudo $\mathrm{R}^{2}$ were calculated using the following equations (Washington et al., 2005).

$$
\begin{aligned}
& M S E=\frac{1}{n_{1}-p} \sum_{i=1}^{n}\left(Y_{i}-Y_{i}^{\prime}\right)^{2} \\
& M A D=\frac{1}{n_{2}} \sum_{i=1}^{n}\left|Y_{i}^{\prime}-Y_{i}\right| \\
& M S P E=\frac{1}{n_{2}-p} \sum_{i=1}^{n}\left(Y_{i}-Y_{i}^{\prime}\right)^{2} \\
& R^{2}=1-\frac{\ln \left(M_{\text {Full }}\right)}{\ln \left(M_{\text {Intercept }}\right)}
\end{aligned}
$$

where;

$$
\begin{aligned}
& n_{1}=\text { training dataset sample size; } \\
& n_{2}=\text { validation dataset sample size; } \\
& p=\text { number of model parameters; } \\
& Y_{i}=\text { observed weaving crashes for } 1 \text { hour; } \\
& Y_{i}^{\prime}=\text { Predicted weaving crashes for } 1 \text { hour; } \\
& \ln \left(M_{\text {Full }}\right)=\log \text {-likelihood of full model; and } \\
& \ln \left(M_{\text {Intercept }}\right)=\log \text {-likelihood of the intercept model }
\end{aligned}
$$

In this study, MAD, MSE and MSPE were normalized to compensate for the different number of years associated with different datasets (Washington et al, 2005). For MAD per year, MAD was divided by number of years, while MSPE and MSE were divided by the square number of years.

\subsection{Crash Modification Factors}

In this study, CMFs were estimated using cross sectional method. In this method, CMFs were estimated directly from the coefficients of the model. This approach assumes that each model variable was independent and not influenced by the value of any other variable. It also assumes that the relationship between the change in the variable value and the change in crash frequency was exponential. The resulting CMFs can yield useful information about the first-order effect of a given variable on safety. The value of CMF was estimated for a particular treatment type using Equation 9 (Lord and Bonneson, 2007 and Al-Marafi, M.N et al, 2018)

$$
C M F_{i}=e^{\beta_{i}\left(X_{i}-X_{i b}\right)}
$$

where,

$X_{i}=$ observed value for the variable $i$;

$X_{i b}=$ the base condition for the variable $i$; 
$\beta_{i}=$ model parameter for the variable $i$

A CMF value greater than 1.0 represents the situation where the design change is associated with more crashes while an CMF less than 1.0 indicates fewer crashes. The standard error (SE) of the CMF for each treatment type was calculated using equation 7. (Harkey et al. 2008, and Park et al., 2015).

$$
S . E_{i}=\frac{e^{\beta_{i}\left(X_{i}-X_{i b}\right)+S E_{\beta i}}-e^{\beta_{i}\left(X_{i}-X_{i b}\right)-S E_{\beta i}}}{2}
$$

where;

S.E $E_{i}=$ standard error of the $\mathrm{CMF}_{i}$;

$S E_{\beta i}=$ standard error of the model parameter $\beta_{i}$

Standard error value less than or equal to 0.1 indicates that CMF result was more reliable.

\section{Results}

\subsection{Developing Crash Frequency Models for Weaving Sections}

Using PROC GENMOD procedure in SAS statistical software (SAS On Demand for Academics, 2020), crash frequency (based on NB model) were developed for freeway weaving sections. Dataset was divided into (70\%) training and $(30 \%)$ validation splits. The final fitted models are shown in table 3 using $70 \%$ training data. Variables that were correlated were removed before developing models. Backward elimination was adopted to identify significant predictor variables. Predictor variables were eliminated if the P-value was greater than 0.10 (level of significance). The response variable in this analysis was considered as crashes per hour in eight years. Table 5 show results for total, rear-end, sideswipe crashes, angle and single-vehicle crash frequency models using NB method.

\subsubsection{Total Crashes}

From Table 5, the coefficient for non-weaving traffic per hour was positive, indicating total crashes per hour increase as non-weaving traffic per hour increases. This is because entry ramp traffic and exit ramp traffic often enter into conflicting situations with non-weaving traffic, resulting in crashes in the weaving sections (Pulugurtha and Bhatt, 2015). On other hand, total crashes per hour decrease as width of inside shoulder increases. Past studies revealed that shoulders placed adjacent to travel lanes were used as emergency stop and pull off, recovery areas for driver error, and pavement edge support (Hadi et al, 1995; and Sacksteder et al, 2009). In addition, the coefficient for the width of outside shoulder was positive, indicating that the number of total crashes per hour increase as the width of outside shoulder increases in the weaving section. This result was appropriate because as the vehicle were trying to merge from on-ramp, wider outside shoulder will cause vehicles to steer closer to center lane causing crashes in the weaving sections. Moreover, Hauer (Hauer, 2000) found that approximately $10 \%$ of fatal freeway crashes were related to vehicles stopped on shoulders. Meanwhile, the coefficient for the weaving ratio was positive, indicating that the number of total crashes per hour increase as the number of weaving vehicles increase i.e., vehicles merging from on-ramp to freeway and diverging from freeway to off-ramp.

\subsubsection{Rear-End Crashes}

Rear-end crashes per hour were positively associated with the off-ramp traffic as shown in Table 5. This implies that the number of rear-end crashes increase with increasing traffic on off-ramp. (Pulugurtha and Bhatt, 2015). This is because, vehicles follow too closely while trying to exit the ramp and travel at higher speeds than the posted speed limit. In addition, the coefficient for non-weaving traffic per hour was positive, indicating rear-end crashes per hour increase as non-weaving traffic per hour increases. Meanwhile, rear-end crashes were negatively associated with southbound side of the limited-access highway. This implies that the likelihood of rear-end crashes on southbound side was less when compared to northbound side of limited-access highway. Furthermore, rear-end crashes were positively correlated with weaving length. This implies that increase in weaving length was leading to more rear-end crashes. In this study, rear-end crashes occurred in longer weaving lengths were associated with wider lanes based on the data. Drivers generally operate at higher speeds in wider lanes and longer lengths causing rear-end crashes while trying to exit the weaving sections (Sackstedar et al, 2009). 
Table 5. NB Analysis for Freeway Weaving Sections

\begin{tabular}{|c|c|c|c|c|c|}
\hline S. No & $\begin{array}{l}\text { Dependent } \\
\text { Variable }\end{array}$ & Independent Variables & Estimate & $\begin{array}{l}\text { Standard } \\
\text { Error }\end{array}$ & P- Value \\
\hline \multirow[t]{6}{*}{1.} & \multirow[t]{6}{*}{ Total crashes } & Intercept & -7.25 & 0.573 & $<0.0001$ \\
\hline & & $\begin{array}{l}\text { Natural logarithm of traffic per hour } \\
\text { (Non-Weaving) }\end{array}$ & 1.19 & 0.08 & $<0.0001$ \\
\hline & & Width of Inside Shoulder & -0.14 & 0.05 & 0.009 \\
\hline & & Width of Outside Shoulder & 0.196 & 0.03 & $<0.0001$ \\
\hline & & Weaving Ratio & 1.26 & 0.507 & 0.01 \\
\hline & & Dispersion & 0.65 & 0.08 & --- \\
\hline \multirow[t]{7}{*}{2.} & \multirow[t]{7}{*}{ Rear-end crashes } & Intercept & -28.19 & 2.04 & $<0.0001$ \\
\hline & & $\begin{array}{l}\text { Natural logarithm of traffic per hour } \\
\text { (Off-Ramp) }\end{array}$ & 0.71 & 0.11 & $<0.0001$ \\
\hline & & $\begin{array}{l}\text { Natural logarithm of traffic per hour } \\
\text { (Non-Weaving) }\end{array}$ & 1.24 & 0.16 & $<0.0001$ \\
\hline & & Freeway (Northbound) ${ }^{\circledR}$ & --- & --- & --- \\
\hline & & Freeway (Southbound) & -0.48 & 0.17 & 0.006 \\
\hline & & $\begin{array}{l}\text { Natural Logarithm of Weaving } \\
\text { Section Length }\end{array}$ & 1.82 & 0.204 & $<0.0001$ \\
\hline & & Dispersion & 0.75 & 0.106 & --- \\
\hline \multirow[t]{6}{*}{3.} & \multirow{6}{*}{$\begin{array}{l}\text { Sideswipe } \\
\text { crashes }\end{array}$} & Intercept & -4.301 & 0.555 & $<0.0001$ \\
\hline & & $\begin{array}{l}\text { Natural logarithm of traffic per hour } \\
\text { (On-Ramp) }\end{array}$ & 0.544 & 0.101 & $<0.0001$ \\
\hline & & $\begin{array}{l}\text { Natural logarithm of traffic per hour } \\
\text { (Off-Ramp) }\end{array}$ & 0.161 & 0.09 & 0.09 \\
\hline & & Width of Outside Shoulder & 0.23 & 0.04 & $<0.0001$ \\
\hline & & Width of Inside Shoulder & -0.23 & 0.08 & 0.006 \\
\hline & & Dispersion & 1.05 & 0.207 & --- \\
\hline \multirow[t]{6}{*}{4.} & \multirow[t]{6}{*}{ Angle crashes } & Intercept & -9.22 & 1.2 & $<0.0001$ \\
\hline & & $\begin{array}{l}\text { Natural logarithm of traffic per hour } \\
\text { (Non-Weaving) }\end{array}$ & 1.155 & 0.17 & $<0.0001$ \\
\hline & & Width of Inside Shoulder & -0.25 & 0.08 & 0.0032 \\
\hline & & Width of Outside Shoulder & 0.174 & 0.04 & 0.0002 \\
\hline & & Weaving Ratio & 2.61 & 0.82 & 0.001 \\
\hline & & Dispersion & 0.72 & 0.23 & --- \\
\hline \multirow[t]{6}{*}{5.} & \multirow{6}{*}{$\begin{array}{ll}\begin{array}{l}\text { Single } \\
\text { crashes }\end{array} & \text { Vehicle }\end{array}$} & Intercept & -17.65 & 2.108 & $<0.0001$ \\
\hline & & $\begin{array}{l}\text { Natural logarithm of traffic per hour } \\
\text { (On-Ramp) }\end{array}$ & 0.32 & 0.06 & 0.0001 \\
\hline & & Freeway (Northbound) ${ }^{\circledR}$ & --- & --- & --- \\
\hline & & Freeway (Southbound) & 0.53 & 0.18 & 0.004 \\
\hline & & $\begin{array}{l}\text { Logarithm of Weaving Section } \\
\text { Length }\end{array}$ & 1.92 & 0.24 & $<0.0001$ \\
\hline & & Dispersion & 0.1 & $0 . .16$ & --- \\
\hline
\end{tabular}

\subsubsection{Sideswipe Crashes}

From Table 5, the coefficient for on-ramp traffic per hour and off-ramp traffic per hour was positive, indicating sideswipe crashes per hour increase as traffic on on-ramp and off-ramp increases. Drivers tend to change lanes while trying to merge from on-ramp to freeway and diverge from freeway to off-ramp in the type-A weaving sections causing sideswipe crashes. Lane change was an important factor affecting sideswipe crashes (Mao et al, 2019). On other hand, sideswipe crashes per hour decrease as width of inside shoulder increases. In addition, the coefficient for the width of outside shoulder was positive, indicating that the number of sideswipe crashes per hour increase as the width of outside shoulder increases in the weaving section.

\subsubsection{Angle Crashes}

Angle crashes per hour were positively correlated non-weaving traffic as shown in Table 5, indicating that angle crashes 
increase as non-weaving traffic increases. Angle crashes occur when drivers trying to diverge from freeway to enter off-ramp and collide with existing vehicles in the auxiliary lane. Similarly, angle crashes could occur when drivers try to merge from on-ramp to freeway and collide with existing vehicles in the interior lanes in type-A weaving sections. On other hand, angle crashes per hour decrease as width of inside shoulder increases. In addition, the coefficient for the width of outside shoulder was positive, indicating that the number of angle crashes per hour increase as the width of outside shoulder increases in the weaving section. Similar results were observed for total crashes and sideswipe crashes in type-A weaving sections. Furthermore, the coefficient for weaving ratio is positive, indicating that the number of angle crashes increase as weaving ratio increases. This result was appropriate because, as more number of vehicles trying to weave in the weaving section, there is a high chance for a driver to involve in an angle crash. Angle crashes could occur when drivers try to merge near the gore area rather than accelerating in the auxiliary sections and change lanes.

\subsubsection{Single-Vehicle Crashes}

From Table 5, the coefficient for on-ramp traffic per hour was positive indicating that single-vehicle crashes increase as traffic on ramp increases in type-A weaving section. The results were contrary to the expectation that traffic merging from on-ramp to main-line traffic has a higher chance for a driver to lose control of the vehicle. In addition, single-vehicle crashes were positively associated with southbound side of the limited-access highway. This implies that the likelihood of single-vehicle crashes on southbound side was more when compared to northbound side of limited-access highway. Furthermore, the coefficient for weaving length is positive, indicating the number of single vehicle crashes increase as length of the weaving section increase. These results show that, drivers were inattentive and travelling at higher speeds in longer weaving sections.

\subsection{Model Goodness-of-Fit Statistics}

Table 6 shows goodness of fit statistics for the training dataset and validation dataset. For the training crash dataset, the negative binomial regression model fits well. The ratios of deviance and Pearson chi-square to degree of freedom (D/DF and $\chi^{2} / \mathrm{DF}$ ) for all the models were close to one, indicating NB model was a good fit for the crash data. MSE and MSE per year squared was also calculated for the training dataset.

Table 6. Goodness-of-Fit Statistics

\begin{tabular}{llllll}
\hline $\begin{array}{l}\text { Assessment } \\
\text { Criterion }\end{array}$ & $\begin{array}{l}\text { Total } \\
\text { Crashes }\end{array}$ & $\begin{array}{l}\text { Rear-end } \\
\text { Crashes }\end{array}$ & $\begin{array}{l}\text { Sideswipe } \\
\text { Crashes }\end{array}$ & $\begin{array}{l}\text { Angle } \\
\text { Crashes }\end{array}$ & $\begin{array}{l}\text { Single-Vehicle } \\
\text { Crashes }\end{array}$ \\
\hline Deviance $(D)$ & \multicolumn{7}{c}{ (Training dataset) } & & \\
\hline Pearson chi-square $\left(\chi^{2}\right)$ & 296.31 & 249.14 & 252.07 & 244.86 & 251.23 \\
\hline Degrees of Freedom (DF) & 350.69 & 322 & 292.53 & 291 & 291.58 \\
\hline D/DF & 288 & 288 & 288 & 288 & 287 \\
\hline$\chi^{2} / \mathrm{DF}$ & 1.02 & 0.86 & 0.87 & 0.85 & 0.86 \\
\hline MSE & 1.2 & 1.1 & 1.01 & 1.01 & 1.008 \\
\hline MSE/yr ${ }^{2}$ & 52.48 & 27.06 & 2.91 & 1.02 & 0.51 \\
\hline & 0.82 & 0.42 & 0.04 & 0.01 & 0.007 \\
\hline MAD & \multicolumn{7}{c}{ (Validation dataset) } & & \\
\hline MAD/yr & 0.25 & 1.81 & 1.01 & 0.58 & 0.29 \\
\hline MSPE & 0.03 & 0.22 & 0.12 & 0.38 & 0.2 \\
\hline MSPE/yr & 5.69 & 13.5 & 2.28 & 0.83 & 0.23 \\
\hline Pseudo-R & 0.08 & 0.21 & 0.03 & 0.01 & 0.003 \\
\hline
\end{tabular}

In addition, prediction performance was assessed for the validation dataset. MAD per year and MSPE per year squared and pseudo- $\mathrm{R}^{2}$ were calculated. The results revealed that MAD and MAD per year for the total crashes validation dataset was lower when compared to rear-end, sideswipe, angle and single-vehicle crashes validation datasets. A comparison of MSE and MSPE revealed that MSPE was lower than the MSE for total crashes, rear-end, sideswipe, angle and single-vehicle validation models. However, MSE per year square and MSPE per year square for sideswipe, angle and sideswipe crashes were similar in magnitude indicating a good fit to the estimation data (Washington et al, 2005). In addition, MSPE and MSPE per year square was lower for single-vehicle crashes when compared to other models. Similar results were observed in scatter plots (figure $6 a, 6 b, 6 c, 6 d$, and $6 e$ ). Figure 6 depicts the prediction performance of total, rear-end, sideswipe, angle and single-vehicle crash models for different times of the day. The scatter plots show observed crashes and predicted crashes against the time of the day. 


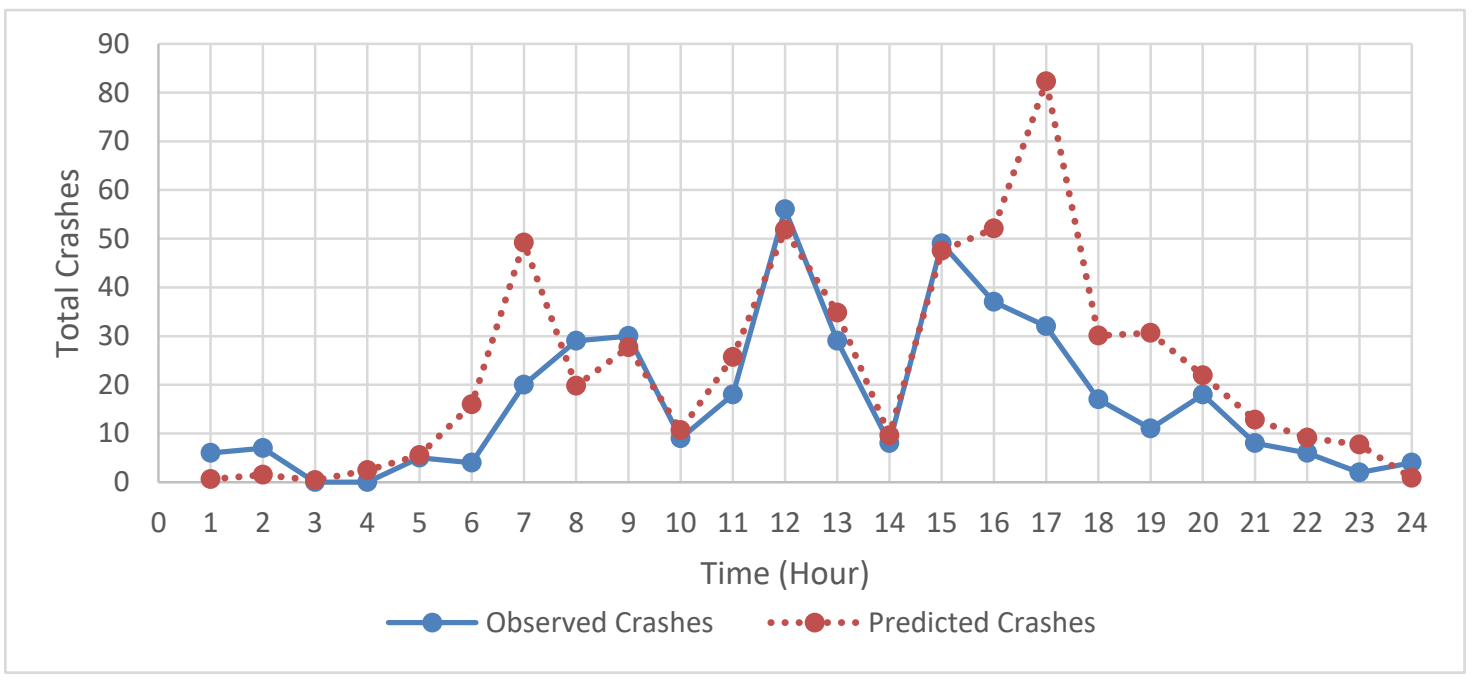

(a)

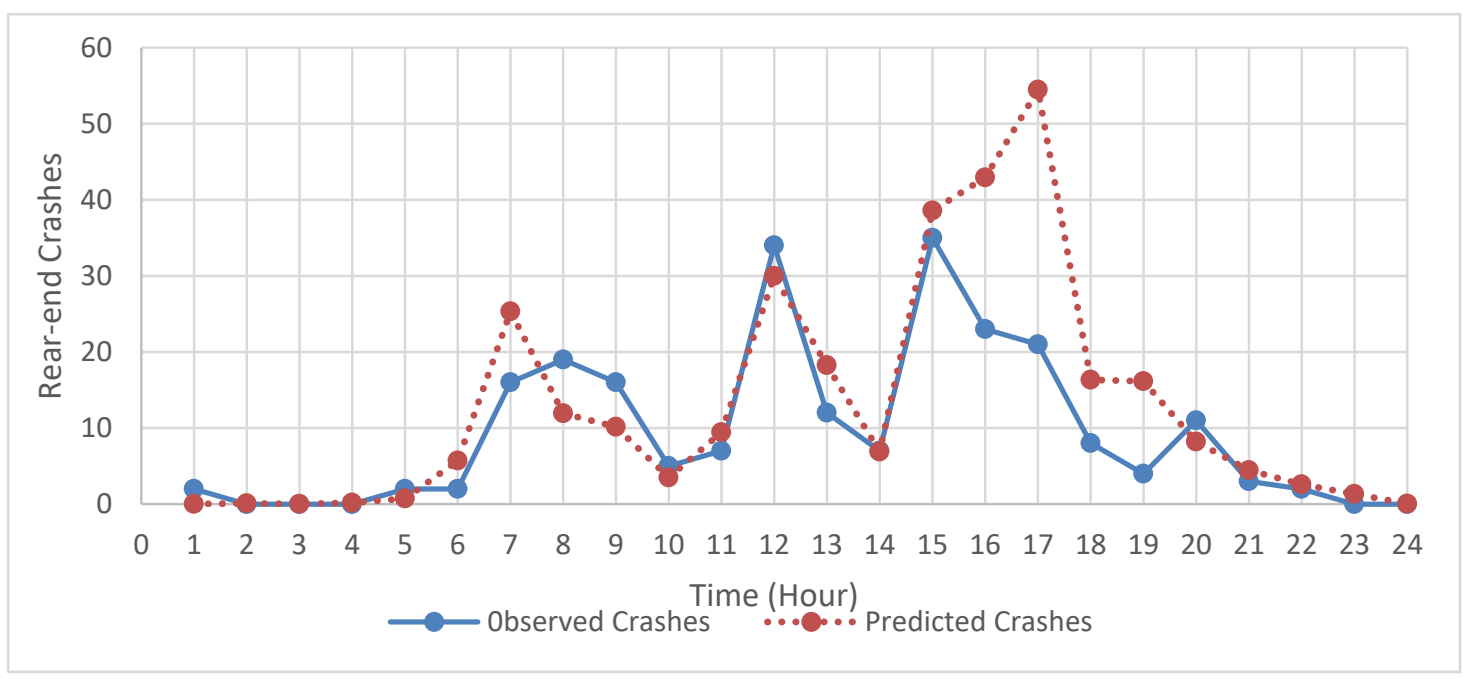

(b)

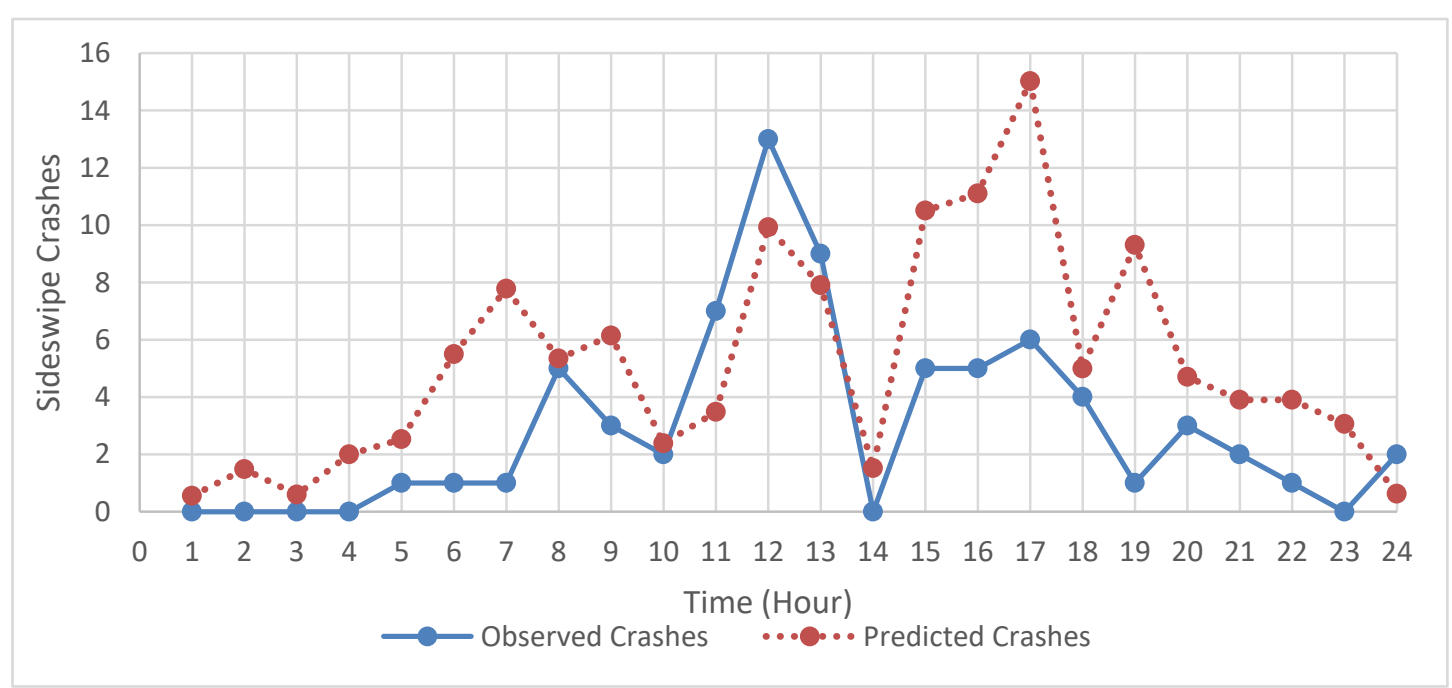

(c) 


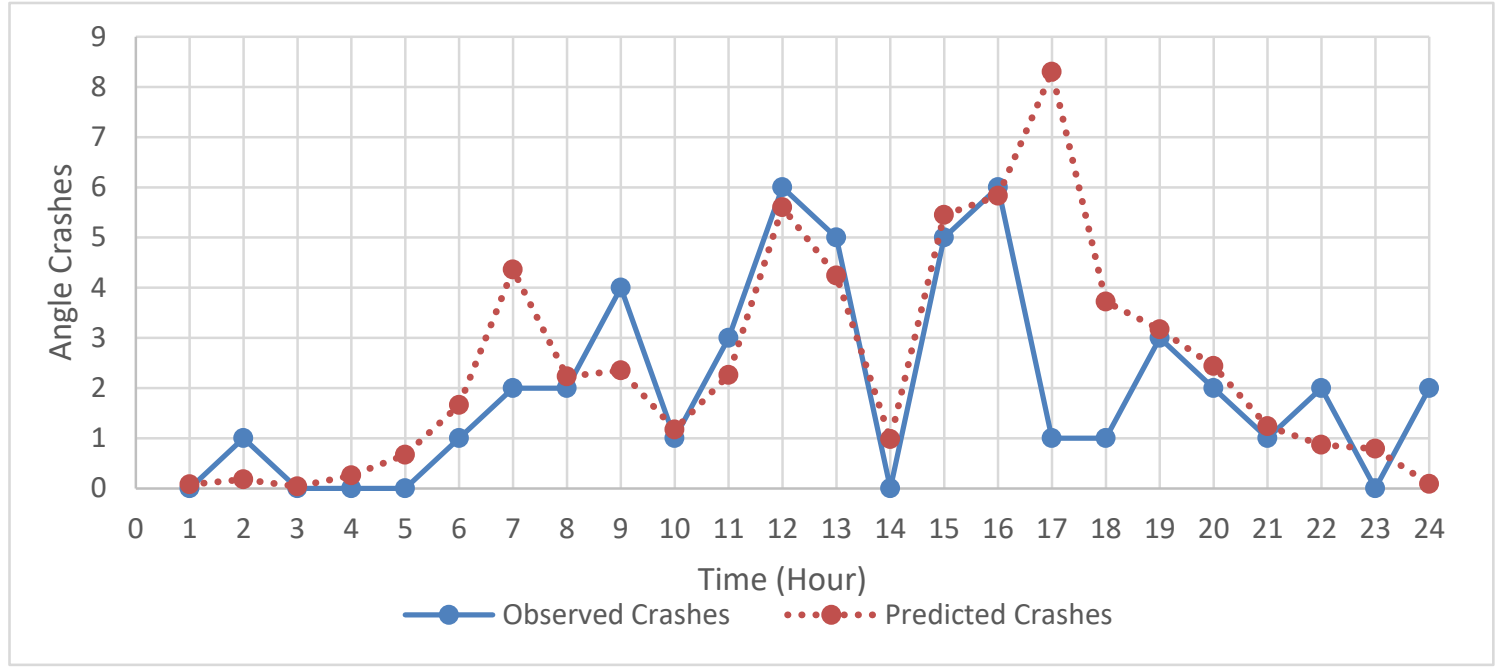

(d)

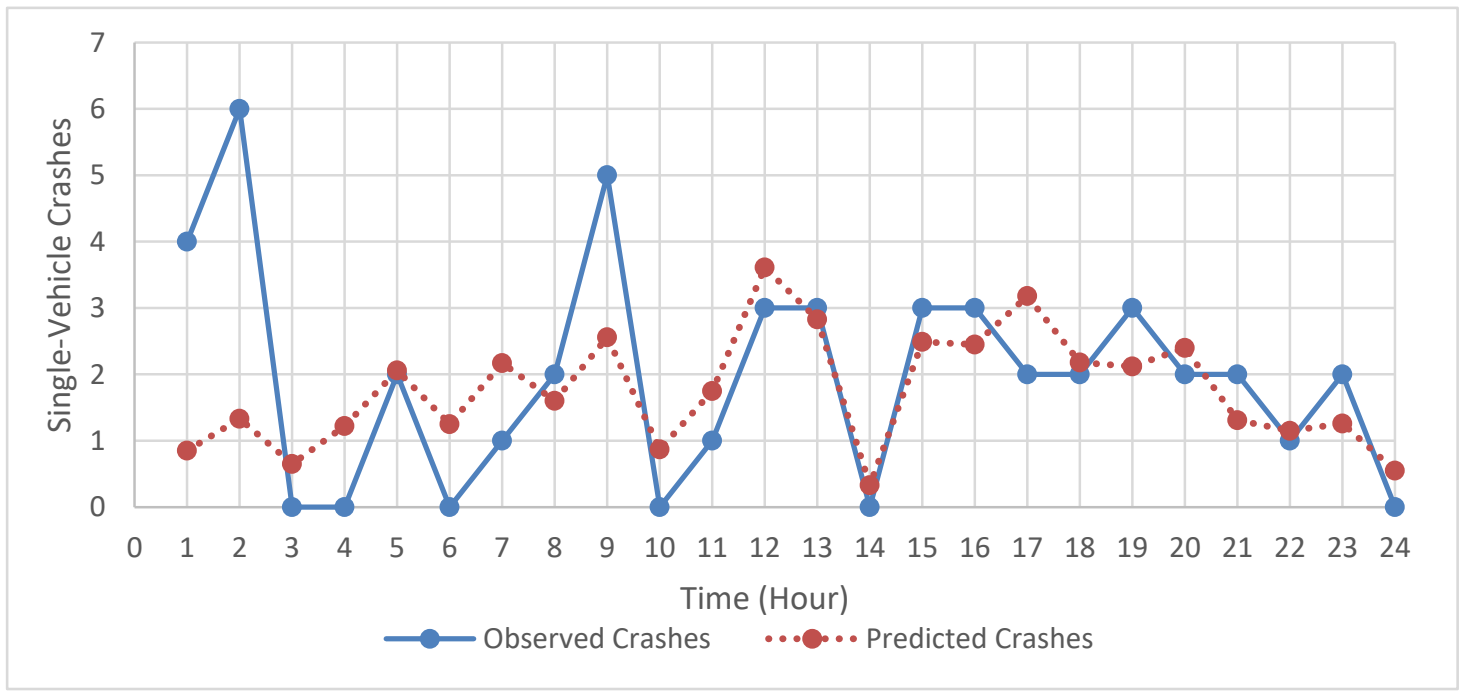

(e)

Figure 6. Scatter Plots of Observed Crashes versus Predicted Crashes (a) Total Crash Model (b) Rear-end Crash Model (c) Sideswipe Crash Model (d) Angle Crash Model (e) Single-Vehicle Crash Model

\subsection{Crash Modification Factors (CMFs)}

Table 7 shows estimated CMFs for widening inside shoulder width and reducing outside shoulder width in the type-A weaving sections using the cross-sectional method. All CMFs were significant at a $90 \%$ confidence interval. For inside shoulder, 1 feet ( $\mathrm{ft}$ ) was chosen as the base line (i.e. $\mathrm{CMF}=1$ ) and $9 \mathrm{ft}$ was chosen as the base line for outside shoulder width. The CMFs were estimated using the coefficients of the total crashes from table 7 . The CMF for widening inside shoulder width was calculated as exp (-0.14). For inside shoulder width of $1 \mathrm{ft}$, a CMF of 1 would indicate $0 \%$ change in crash frequency, and for inside shoulder width of 2 feet, a CMF of 0.86 would indicate $14 \%$ reduction in crash frequency. For outside shoulder width of $1 \mathrm{ft}$, a CMF of 0.21 would indicate $79 \%$ reduction in crash frequency when compared to outside shoulder width of $9 \mathrm{ft}$. 
Table 7. Estimated CMFs for Inside Shoulder and Outside Shoulder Width

\begin{tabular}{llllll}
\hline Inside Shoulder Width & \multicolumn{2}{l}{ Total Crashes } & \multicolumn{2}{l}{ Outside Shoulder Width } & \multicolumn{2}{l}{ Total Crashes } \\
\hline & CMF & S.E & & CMF & S.E \\
\hline $\begin{array}{l}1 \mathrm{ft} \\
\text { (Base Condition) }\end{array}$ & 1 & --- & $1 \mathrm{ft}$ & 0.21 & 0.02 \\
\hline $2 \mathrm{ft}$ & & & & & 0.26 \\
\hline $3 \mathrm{ft}$ & 0.86 & 0.05 & $2 \mathrm{ft}$ & 0.31 & 0.03 \\
\hline $4 \mathrm{ft}$ & 0.75 & 0.051 & $3 \mathrm{ft}$ & 0.38 & 0.032 \\
\hline $5 \mathrm{ft}$ & 0.65 & 0.05 & $4 \mathrm{ft}$ & 0.46 & 0.03 \\
\hline $6 \mathrm{ft}$ & 0.57 & 0.04 & $5 \mathrm{ft}$ & 0.56 & 0.033 \\
\hline $7 \mathrm{ft}$ & 0.49 & 0.04 & $6 \mathrm{ft}$ & 0.68 & 0.03 \\
\hline $8 \mathrm{ft}$ & 0.43 & 0.04 & $7 \mathrm{ft}$ & 0.82 & 0.03 \\
\hline $9 \mathrm{ft}$ & 0.37 & 0.04 & $8 \mathrm{ft}$ & 1 & --- \\
\hline
\end{tabular}

--- "Not Applicable"

Figure 7(a) shows that total crashes CMFs gradually decrease as inside shoulder width increases. This implies that widening shoulder width have positive effects on weaving section safety. Meanwhile, total crashes CMFs gradually increase as outside shoulder width increases in type-A weaving section indicating that wider outside shoulder widths have negative impacts on weaving sections safety.

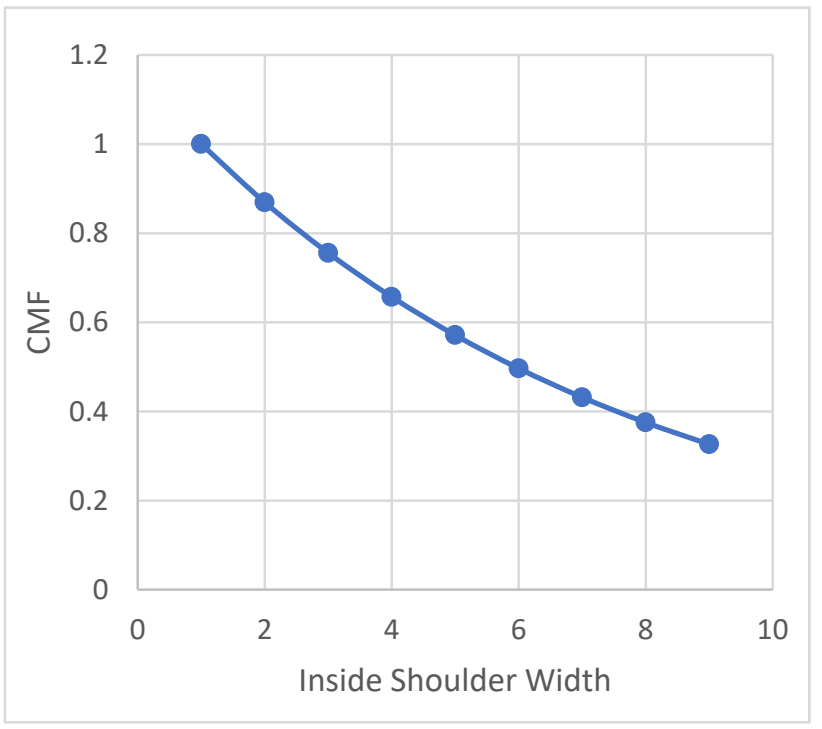

(a)

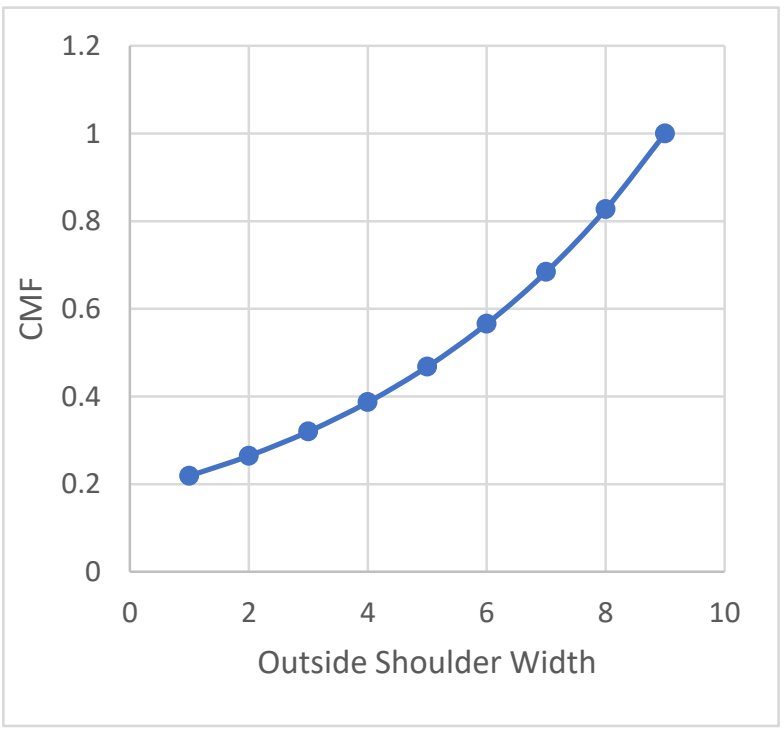

(b)

Figure 7. Crash Modification Factors for (a) Inside Shoulder Width (b) Outside Shoulder Width in the type-A Weaving Sections

\section{Conclusion}

In this study, to better understand critical movements in the type-A weaving sections at different times of day, time-of-day factors were included from NCHRP 365 to the dataset. Traffic volumes and crashes were segregated by 24-hour periods in seventeen type-A weaving sections. NB regression method was used for estimating expected crash frequency per hour in a year. Eight years (2010-2017) of type-A weaving crash data was used in the analysis. Crash data was divided into $70 \%$ of training data and $30 \%$ of validation data to analyze prediction performance of the estimates. The objective of this study was to find the factors influencing the total crashes, rear-end crashes, sideswipe crashes, angle crashes and single-vehicle crashes and provide CMFs to reduce the crashes in the type-A weaving sections.

The results revealed that non-weaving traffic per hour, width of inside shoulder, width of outside shoulder and weaving ratio factors were influencing the total crash frequency in type-A weaving sections. For rear-end crash frequency model, off-ramp traffic per hour, non-weaving traffic per hour, direction of freeway and length of the weaving section were found significant. In addition, on-ramp traffic per hour, off-ramp traffic per hour, width of inside shoulder, and width of the outside shoulder were found influencing the sideswipe crash frequency. For angle crash frequency model, non-weaving traffic per hour, width of inside shoulder, width of the outside shoulder and weaving ratio were influencing 
the angle crashes in the type-A weaving sections. For single-vehicle frequency model, on-ramp traffic per hour, direction of freeway and length of the weaving section were found influencing the single-vehicle crashes. Non-weaving traffic per hour, width of inside shoulder and width of outside shoulder appeared to play a prominent role in explaining most crash types in the type-A weaving section.

Goodness-of-fit assessment for the training data revealed that the ratios of deviance and Pearson chi-square to degree of freedom (D/DF and $\chi^{2} / \mathrm{DF}$ ) for all the models were close to one, indicating NB model was a good fit for the crash data. Meanwhile, assessment of the validation data revealed that the prediction performance MSPE and MSPE per year were lower for single-vehicle crash dataset when compared to total, rear-end, angle and sideswipe crash datasets.

Furthermore, CMFs were developed total crashes in type-A weaving sections to know the change in safety when a geometric design element changes in size from one value to another. In this study, CMFs were developed using cross-sectional method i.e. CMFs were estimated directly from the coefficients of the model developed using NB model. The results revealed that total crashes CMFs gradually decrease as inside shoulder width increases. This implies that widening shoulder width have positive effects on weaving section safety. Meanwhile, total crashes CMFs gradually increase as outside shoulder width increases in type-A weaving section indicating that wider outside shoulder widths have negative impacts on weaving sections safety.

Apart from geometric design changes, the following recommendations were suggested to reduce crashes in type-A weaving sections:

- Ramp metering helps in separating non-weaving traffic and weaving traffic movement over space and time, to reduce sideswipe crashes and angled crashes.

- Advisory warning signs and variable speed limits should be displayed during congested times to reduce rear-end crashes and crashes due to excessive speeding

In the future, this study can be extended to investigate factors that are influencing crashes in freeway type-A, type-B and type-C weaving sections in the state of Alabama, rather than just limited to regional sites. However, this study can be used as a reference to improve safety in weaving sections. Furthermore, driver characteristics, crash characteristics, vehicle characteristics and environmental characteristics can be analyzed, to find out factors that were influencing crashes in the weaving sections.

\section{Acknowledgement}

The authors would like to acknowledge the Alabama Department of Transportation (ALDOT) for providing the crash and traffic data used in this study. The opinions, findings, and conclusions in this paper are those of the authors and not necessarily those of the State of Alabama Department of Transportation.

\section{References}

Abbas, N. (2016). Development of Safety Performance Functions for High-Speed Roadways in Saskatchewan. (Master Thesis, University of Saskatchewan, Saskatoon, Canada). Retrieved from https://harvest.usask.ca/handle/10388/7293

Al-Marafi, M. N., Somasundaraswaram, K., \& Ayers, R. (2020). Developing Crash Modification Factors for Roundabouts using a Cross-Sectional Method. Journal of Traffic and Transportation Engineering, 7(3), 362-374. https://doi.org/10.1016/j.jtte.2018.10.012

Cirillo, J. (1970). The Relationship of Accidents to Length of Speed-Change Lanes and Weaving Areas on Interstate Highways. Highway Research Record., 312, 17-32. http://onlinepubs.trb.org/Onlinepubs/hrr/1970/312/312-002.pdf

Cassidy, M., \& May, A. (1991). Proposed Analytical Technique for Estimating Capacity and Level of Service of Major Freeway Weaving Sections. Transportation Research Record: Journal of the Transportation Research Board, 1320, 99-109. http://onlinepubs.trb.org/Onlinepubs/trr/1991/1320/1320-013.pdf
ArcMap
10.2 .
(2019).
ESRI.
Accessed.
July
10 ,
2019. http://support.esri.com/en/Products/Desktop/arcgisdesktop/arcmap/10-2-2

Fitzpatrick, K., \& Nowlin, L. (1995). One Sided Weaving Analysis on One-Way Frontage Roads. Texas Department of Transportation, Report FHWA/TX-96/1393-1, Retrieved from https://static.tti.tamu.edu/tti.tamu.edu/documents/1393-1.pdf

Golob, T. F., Recker, W., \& Alvarez, V. (2004). Safety Aspects of Freeway Weaving Sections. Transportation Research Part A., 38, 35-51. https://doi.org/10.1016/j.tra.2003.08.001

Google Earth Pro V 7.3. (2019). Google Earth Pro Application. Accessed August 1, 2019, https://www.google.com/earth/ 
Hadi, M., Aruldhas, J., Chow, L., \& Wattleworth, J. (1995). Estimating Safety Effects of Cross-Section Design for Various Highway Types using Negative Binomial Regression. Transportation Research Record: Journal of the Transportation Research Board, 1500, 169-177. https://trid.trb.org/view/452743

Harkey, D. L., Srinivsan, R., Baek, J., Council, F. M., Eccles, K., Lefler, N., E., ... Bonneson, J. A. (2008). Accident Modification Factors for Traffic Engineering and ITS Improvements. National Academics of Sciences, Engineering, and Medicine. https://dx.doi.org/10.17226/13899

Iliadi, A., Farah, H., Schepers, P., \& Hoogendoorn, S. (2016). A Crash Prediction Model for Weaving Sections in the Netherlands. Proceedings of the $95^{\text {th }}$ Annual Meeting of the Transportation Research Board, https://trid.trb.org/view/1392588

Juneyoung, P. (2015). Exploration and Development of Crash Modification Factors and Functions for Single and Multiple Treatments. (Electronic Thesis and Dissertations, University of Central Florida, Florida, USA). Retrieved from https://stars.library.ucf.edu/etd/706/

Kutner, M. H., Nachtscheim, C. J., Neter, J., \& Li, W. (2005). Applied Linear Statistical Models. (5th ed.). New York, NY: McGraw-Hill Irwin.

Lord, D., \& Bonneson, J. A. (2007). Development of Accident Modification Factors for Rural Frontage Road Segments in Texas. Transportation Research Record: Journal of the Transportation Research Board, 2023, 20-27. https://journals.sagepub.com/doi/10.3141/2023-03

Le, T., \& Porter, R. (2012). Safety Evaluation of Geometric Design Criteria for Spacing of Entrance-Exit Ramp Sequence and Use of Auxiliary Lanes. Transportation Research Record: Journal of the Transportation Research Board, 2309, 12-20. https://journals.sagepub.com/doi/10.3141/2309-02

Mao, X., Yuan, C., Gan, J., \& Zhang, S. (2019). Risk Factors Affecting Traffic Accidents at Urban Weaving Sections: Evidence from China. International Journal of Environmental Research and Public Health, 16(9). https://www.mdpi.com/1660-4601/16/9/1542

Mallipaddi, V., \& Anderson, M. (2020). Analysis of Crashes on Freeway Weaving Sections. Proceedings of the International Conference on Transportation and Development 2020: Transportation Safety. https://doi.org/10.1061/9780784483145.014

Qin, X., Ivan, J., Ravishankar, N., Liu, J., \& Tepas, D. (2006). Bayesian Estimation of Hourly Exposure Functions by Crash Type and Time of Day. Accident Analysis and Prevention, 38, 1071-1080. https://doi.org/10.1016/j.aap.2006.04.012

Qi, Y., Liu, J., \& Wang, Y. (2014). Safety Performance of Freeway Weaving Segments. Southwest Region University Transportation Center, Report SWUTC/14/600451-00045-1. Retrieved from https://static.tti.tamu.edu/swutc.tamu.edu/publications/technicalreports/600451-00045-1.pdf

Park, B., Fitzpatrick, K., \& Lord, D. (2010). Evaluating the effects of Freeway Design Elements on Safety. Transportation Research Record: Journal of the Transportation Research Board, 2195(1), 58-69. https://journals.sagepub.com/doi/abs/10.3141/2195-07

Park, J., Abdel-Aty, M., \& Lee, J. (2015). Bayesian Developing Crash Modification Functions to Assess Safety Effects of Adding Bike Lanes for Urban Arterials with Different Roadway and Socio-Economic Characteristics. Accident Analysis and Prevention, 74, 179-191. https://doi.org/10.1016/j.aap.2014.10.024

National Highway Traffic Safety Administration. (2019). Traffic Safety Facts 2007. Retrieved from http://www-nrd.nhtsa.dot.gov/

Pulugurtha, S., \& Bhatt, J. (2010). Evaluating the Role of Weaving Section Characteristics and Traffic on Crashes in Weaving Areas. Traffic Injury Prevention., 11(1), https://www.tandfonline.com/doi/abs/10.1080/15389580903370039

Roess, R. P., Prassas, E. S., \& McShane, W. R. (2004). Traffic Engineering. (4th ed.). Pearson Higher Education, Upper Saddle River, NJ: Pearson Higher Education.

Stewart, J., Baker, M., \& Van Aerde, M. (1996). Evaluating Weaving Section Design using Integration. Transportation Research Record: Journal of the Transportation Research Board, 1555, 33-41. https://journals.sagepub.com/doi/10.1177/0361198196155500105

Sackstedar, J., Ruff, W., \& Lord, D. (2009). Impact of Shoulder Width and Median Width on Safety. American Association of State Highway and Transportation Officials, Report 633. Retrieved from https://www.nap.edu/catalog/14252/impact-of-shoulder-width-and-median-width-on-safety 
Shirani-bidabadi, N., Mallipaddi, N., Haleem, K., \& Anderson, M. (2020). Developing Bicycle-Vehicle Crash- Specific Safety Performance Functions in Alabama Using Different Techniques. Accident Analysis and Prevention, 146, 1-13. https://doi.org/10.1016/j.aap.2020.105735

SAS OnDemand for Academics. (2020). SAS, Accessed July 10, 2020. https://doi.org/10.1007/978-1-4842-5925-2_3

Tarko, A., Eranky, S., \& Sinha, K. (1998). Methodological Considerations in the Development and Use of Crash Reduction Factors. Proceedings of the $77^{\text {th }}$ Annual Meeting of the Transportation Research Board, https://engineering.purdue.edu/ tarko/research/conf_papers/TRB_meetings/1998-0578.PDF

William, A. M., \& Nancy, A. M. (1998). Travel Estimation Techniques for Urban Planning. American Association of State Highway and Transportation Officials, Report 365, Retrieved from http://www.trb.org/Publications/Blurbs/167061.aspx

Washington, S., Persuad, B., Lyon, C., \& Oh, J. (2005).Validation of Accident Models for Intersections. Federal Highway Administration, Report FHWA-RD-03-037. Retrieved from https://www.fhwa.dot.gov/publications/research/safety/03037/execsum.cfm

\section{Copyrights}

Copyright for this article is retained by the author(s), with first publication rights granted to the journal.

This is an open-access article distributed under the terms and conditions of the Creative Commons Attribution license (http://creativecommons.org/licenses/by/4.0/). 